\title{
A Local Relapse of Small Cell Neuroendocrine Carcinoma of Larynx. "The Tortoise and the Hare"
}

Tebra Mrad Sameh ${ }^{1 *}$, Cherif Mohamed Aziz ${ }^{1}$, Bouzid Nadia ${ }^{1}$, Trimeche Mounir ${ }^{2}$ and Bouaouina Noureddine ${ }^{1}$

${ }^{1}$ Radiation Therapy Department, Farhat Hached Sousse Teaching Hospital, Tunisia

${ }^{2}$ Pathology Department, Farhat Hached Sousse Teaching Hospital, Tunisia

\begin{abstract}
The primitive Small Cell Neuroendocrine Carcinoma (SCNC) is a rare subtype of neuroendocrine laryngeal tumors which are the second most common laryngeal neoplasm after squamous cell carcinoma. We report a case of SCNC of the larynx occurring in a 35-year-old man, who smokes and drinks alcohol, who presented with dysphonia and dyspnea. On clinical examination there were painless, mobile cervical lymph nodes in addition to gynecomastia. On endoscopy, the lesion was exophytic and involved the whole of the right vocal cord. SCNC diagnosis was based on morphologic and immune-histochemical criteria. Treatment was non-surgical based on sequential chemoradiation therapy. An isolated local relapse was, unexpectedly, the first post therapeutic event, occurring at the end of the first year of follow up and managed by salvage surgery. Metastatic-free survival was 28 months.
\end{abstract}

Keywords: Small cell carcinoma; Larynx; Relapse

\section{Introduction}

Laryngeal neuroendocrine tumors are less frequent than their classical epidermoid counterpart. They account for about $1 \%$ of all laryngeal cancers [1]. According to Ferlito [2], they are divided into two groups: those of epithelial origin (represented by typical and atypical carcinoid tumors and small cell neuroendocrine carcinoma (SCNC)) and those of neural origin (paraganglioma). All these heterogeneous subgroups have different morphologic, immune-histochemical and prognostic characteristics. SCNC is the most aggressive subtype with a poor outcome and rapid metastatic spread [3]. In this paper, we report an uncommon evolution of this rare malignancy characterized by a local recurrence preceding metastatic dissemination.

\section{Case Report}

A 35-year-old man, heavy smoker and alcohol consumer, with a sixmonth history of dysphonia and dysphagia, was admitted on July $31^{\text {st }}$, 2009 to the ENT Department of Farhat Hached University Hospital, Sousse, Tunisia, with a suffocating laryngeal dyspnea that required tracheotomy. Physical examination revealed large, mobile and painless left cervical lymph nodes as well as gynecomastia. Laryngoscopic examination showed an exophytic lesion involving the whole of the right vocal cord and supraglottic region.

A Computed Tomography (CT) scan of the neck revealed a focal and well circumscribed thickness of the right vocal cord with ipsilateral supraglottic extension (Figure 1). Diagnosis was made by histology which showed nests and cordons of small monomorphic cells, with round hyperchromatic nuclei and scanty basophilic cytoplasm with frequent mitoses (Figure 2). This was confirmed by immunohistochemical analysis revealing a strong positivity to chromogranin (Figure 3a) and cytokeratin (Figure 3b). There was no evidence of a pulmonary primitive tumor on bronchial endoscopy or CT-Scan of the chest. The patient received 3 cycles of Cisplatinium-Etopside between 28/09/2009 and 29/10/2009 followed by cervical externalbeam radiation delivered from $15 / 12 / 2009$ to $12 / 03 / 2010$. The dose was 70.2 Grays to the larynx, 66.6 Grays to the left cervical lymphatic areas and 55.8 Grays to the right ones. The patient was routinely followed up. During the last week of February 2011 he developed acute dyspnea which became suffocating and he needed a new tracheotomy on March $3^{\text {rd }}$, 2011. Laryngoscopic examination revealed a horseshoeshaped exophytic tumor involving both of vestibular folds. Cervical CT scan showed a circumferential glottic tumoral process infiltrating the subglottic level (Figure 4). Biopsy confirmed the local relapse. On the basis of a new work up assessment, there was no evidence of any metastatic spread.

Salvage laryngectomy plus cervical lymphadenectomy were performed on April $4^{\text {th }}$, 2011. Histology showed the tumor involving the whole of the right vocal cord with involvement of thyroid cartilage anteriorly, left vocal cord posteriorly and partial subglottic infiltration.

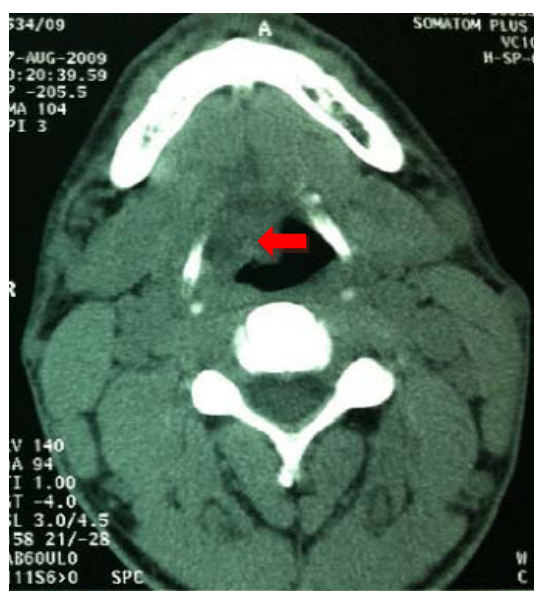

Figure 1: Initial cervical CT-scan transversal section showing the supraglottic extension of the tumor.

*Corresponding author: Tebra Mrad Sameh, Radiation Therapy Department Farhat Hached Sousse Teaching Hospital, Tunisia, E-mail: tebrasameh@yahoo.fr Received November 01, 2011; Accepted April 23, 2012; Published April 26, 2012

Citation: Sameh TM, Aziz CM, Nadia B, Mounir T, Noureddine B (2012) A Local Relapse of Small Cell Neuroendocrine Carcinoma of Larynx. "The Tortoise and the Hare”. J Nucl Med Radiat Ther 3:127. doi:10.4172/2155-9619.1000127

Copyright: (C) 2012 Sameh TM, et al. This is an open-access article distributed under the terms of the Creative Commons Attribution License, which permits unrestricted use, distribution, and reproduction in any medium, provided the original author and source are credited. 


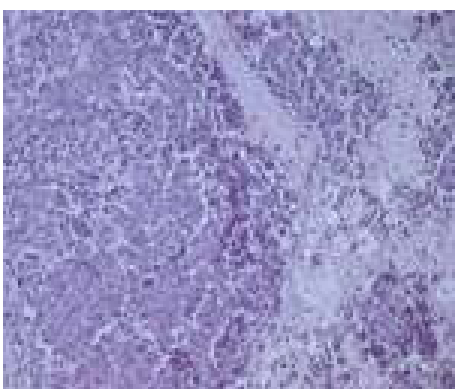

Figure 2: Microscopic study showing nests and cordons of small cells monomorphicand round with hyperchromatic nuclei and scanty basophilic cytoplasm with frequent mitoses.

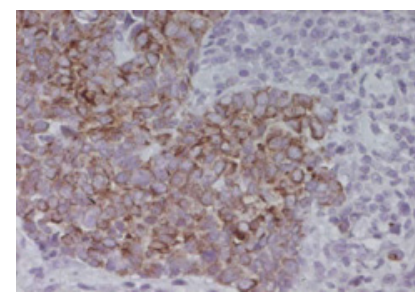

Figure 3: Immunohistochemical analysis revealing diffuse cytoplasmic chromogranine positivity (neuroendocrine marker) (a) and cytokeratin (b)

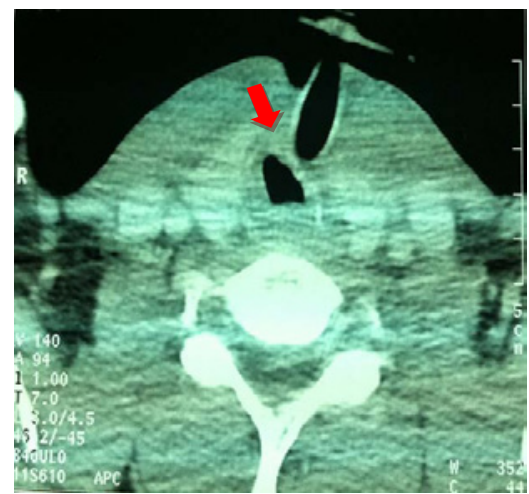

Figure 4: Cervical CT-scan section showing subglottic infiltration by the tumoral relapse as circumferential mucosal thickness especially regarding the tracheostomy.

The margins were negative as well as eight dissected lymph nodes. After a disease-free period of eight months, the patient suffered from an acute headache in December 2011. Cerebral CT-scan was performed and revealed cerebral metastatic dissemination. Corticosteroids were prescribed and palliative cerebral radiation therapy was planned.

\section{Discussion}

SCNC probably arises from the argyrophilic Kultchky's cells dispersed in the laryngeal epithelium [4,5]. The larynx is one of the commonest sites for extra pulmonary small cell carcinomas $[5,6]$. Elimination of any SCNC at pulmonary level is a required condition for diagnosis of a primitive SCNC [7].

The profile of our patient was similar to that described in the literature in terms of risk factors (smoking and alcohol consumption), preferential tumoral site (supraglottic level) and clinical presentation (dysphonia, dyspnea and presence of pathologic cervical lymph nodes at presentation) [3]. It was previously reported that SNCN occurred usually in fifth-decade patients or more. Our patient was 15 years younger than this average. Similarly to lung SCNC, its laryngeal counterpart could be associated to paraneoplastic syndromes such as Schwartz-Bartter syndrome [8], Lamber-Eaton syndrome [9] or Cushing syndrome [10]. Gynecomastia associated with laryngeal SCNC, as encountered in our case, has never been described before.

Histological diagnosis is based on morphologic and immunehistochemical use of cytokeratin markers for epithelial tumors and neuroendocrine markers such as synaptophysin, chromogranin, monoclonal antibodies reactive with enolase [11-13]. SCNC of the larynx is an aggressive epithelial neoplasm with poor prognosis and fatal clinical course classically characterized by precocious metastatic spread $[14,15]$. Uncommonly, our patient developed an isolated local relapse as a first event. Two hypotheses could explain this unexpected evolution:

1) Sequential chemo-radiation therapy might not be as optimal as concurrent chemo-radiation therapy.

2) The vocal cord (site of the initial tumor and relapse) is probably a chemo-resistant site because of its poor vascularization.

Concerning the cerebral metastatic dissemination we wonder about the benefit of prophylactic whole brain irradiation in terms of survival considering what has been demonstrated in lung SCNC.

\section{Conclusion}

Primitive SCC of the larynx is the most lethal neuro-endocrine neoplasm and its risk factors are smoking and alcohol consumption. Symptoms and signs are similar to other laryngeal neoplasms with a possible association with various paraneoplastic syndromes. Diagnosis is based on histology and confirmed by immuno-histochemical analysis. Unlike our case, regardless of the poor outcome of this cancer, first treatment ideally should be based on chemotherapy and concurrent high dose radiation therapy to cervical lymph nodes to ensure local control in order to avoid salvage surgery altering the quality of life. Prophylactic whole brain radiation therapy may be proposed as an option to improve the survival of favorable cases.

\section{References}

1. Ferlito A, Devaney KO, Rinaldo A (2006) Neuroendocrine neoplasms of the larynx: Advances in identification, understanding, and management. Ora Oncol 42: 770-788.

2. Ferlito A, Rosai J (1991) Terminology and classification of neuroendocrine neoplasms of the larynx. ORL J Otorhinolaryngol Relat Spec 53: 185-187.

3. Ferlito A, Rinaldo A (2005) The spectrum of endocrinocarcinomas of the larynx. Oral Oncol 41: 878-883.

4. Ferlito A, Recher G, Caruso G (1985) Primary combined small cell carcinoma of the larynx. Am J Otolaryngol 6: 302-308.

5. Ferlito A (1986) Diagnosis and treatment of small cell carcinoma of the larynx a critical review. Am Otol Rhinol Laryngol 95: 590-600.

6. Gnepp DR, Ferlito A, Hyams V (1983) Primary anaplastic small cell (oat cell) carcinoma of the larynx. Review of the literature and report of 18 cases. Cancer 51: 1731-1745.

7. Braier M, Melnyk P, Yamil O, Fernandez P (2003) Primitive small cell larynx tumor: presentation of a case and literature review. International Congress Series 1240: 1063-1066. 
Citation: Sameh TM, Aziz CM, Nadia B, Mounir T, Noureddine B (2012) A Local Relapse of Small Cell Neuroendocrine Carcinoma of Larynx. "The Tortoise and the Hare". J Nucl Med Radiat Ther 3:127. doi:10.4172/2155-9619.1000127

Page 3 of 3

8. Myers TJ, Kessimian N (1995) Small cell carcinoma of the larynx and ectopic antidiuretic hormone secretion. Otolaryngol Head Neck Surg 113: 301-304.

9. Medina JE, Moran M, Goepfert H (1984) Oat cell carcinoma of the larynx and Eaton-Lambert syndrome. Arch Otolaryngol 110: 123-126.

10. Bishop JW, Osamura RY, Tsutsumi Y (1985) Multiple hormone production in an oat cell carcinoma of the larynx. Acta Pathol Jpn 35: 915-923.

11. Morice WG, Ferreiro JA (1998) Distinction of basaloid squamous cell carcinoma from adenoid cystic and small cell undifferentiated carcinoma by immunochemistry. Human Pathol 29: 609-612.
12. Weidauer H, Blobel GA, Nemetschek-Gansler H, Gould VE, Mall G (1985) Neuroendocrine larynx cancer of small cell (oat cell) type. Morphologic and immunohistochemical findings and their significance for therapy. Laringo Rhinol Otol (Stuttg) 64: 121-127.

13. Overholt SM, Donovan DT, Schwartz MR, Laucirica R, Green LK, et al. (1995) Neuroendocrine neoplasm of larynx. Laryngoscope 105: 789-794.

14. Ferlito A, Rinaldo A (2003) Small cell neuroendocrine carcinoma of the larynx a preventable and frustrating disease with a highly aggressive lethal behavior. Orl J Otorhinolaryngol Relat Spec 65: 131-133.

15. Bone RC, Deer D (1978) Oat cell carcinoma of the larynx. Laryngoscope 88 1190-1195. 